\title{
The Development Of Proof Teaching Materials For High School Students
}

\author{
Lia Hamimi ${ }^{1}$, Riezky Purnama Sari ${ }^{1}$ \\ \{Riezkypurnamasari@gmail.com\} \\ ${ }^{1}$ Mathematic Education Department of High School of Teacher Training and Education of \\ Muhammadiyah South West Aceh, Indonesia
}

\begin{abstract}
Mathematical proof is one aspect that must be considered in learning mathematics in school. One of the obstacles that students experience on geometry is the difficulty in constructing evidence. One of the causes is not yet available evidence-specific teaching materials. As for achieving the purpose is required proof material. This research was conducted to develop the material of proof and develop students' geometry abilities. This research is a development research using ADDIE model consisting of five stages. The first stage is Analysis, the activities undertaken is to analyze the needs, characteristics of students, syllabus, and materials. The second stage is Design, the activities undertaken is to arrange the teaching materials in the form of the initial product. The third stage of Development, the activities undertaken is the validation process of the validator that aims to obtain a valid teaching material. After the validation is obtained prototype 1 . The fourth stage is Implementation, the activities undertaken are trial legibility group and field trials aimed at obtaining practical and effective teaching materials. After the trial to the reading is obtained prototype 2 . After the field trial obtained prototype 3 . The fifth stage of Evaluation, the activities undertaken is to analyze the data of practicality and effectiveness, then produced a valid final prototype, practical and effective. The test subjects in this study were students of class XII-4 MAN Model Banda Aceh 1. Based on the result of research, it is found that the developed teaching material is categorized as valid, practical and effective.
\end{abstract}

Keywords: Proof of Geometry Transformation

\section{Introduction}

Proof is indispensable in mathematics, because one of the mathematical goals according to Permendiknas no 22 of 2006 is to use reasoning on patterns and traits, perform mathematical manipulations in generalizing, compiling evidence, explaining mathematical ideas and statements. Through the process of proof is obtained the development of the ability to think mathematics. Thus mathematical proof is one aspect that must be considered in learning mathematics. Evidence is a series of logical arguments that explain the truth of a statement. Logical means every step in the argument is justified by the previous steps (Juandi, 2008). These arguments can be derived from the premise of the statement itself, other theorems, 
definitions, and finally can be derived from the postulate where the mathematical system originated. Initially the learning using prove only implemented at the level of students in college. This view can be seen in the National Council of Teachers of Mathematics (NCTM) in 1989 because school students are not yet able to construct various forms of reasoning about proof (Suyitno, 2007). However, that opinion was finally updated by [1] on the need for proofof-education at all levels of education described in the "Reasoning and Proof " section that students should be able to: (1) recognize reasoning and proof as fundamental aspects of mathematics, (2) conjecture and examine the truth of the conjecture, (3) develop and evaluate arguments and mathematical proofs, and (4) select and use various types of reasoning and verification methods.

The NCTM recommendation provides guidance that mathematical proofing is an aspect to be considered in mathematics learning in schools. Student experience in high school in making the proof will have an impact on the ability to prove when students attend college. This is in line with that expressed by [2] that one of the reasons why students encounter difficulties in proof is their experience in constructing limited evidence on the proof of school geometry alone. One of the materials that uses proof is geometry. According to [1] that every country including Indonesia introduces geometry in the mathematics curriculum as a science that specifically develops reasoning abilities, arguments, and proof theorems. According to [3] that the emphasis of learning geometry lies in the proof of the theorem, namely the alleged intuitive and logical guessing, understand the logic system and recall the material ever studied.

One of the obstacles that students experience on geometry is the difficulty in constructing evidence. This is supported by the results of research Suwanti (2016) indicating that in the case of constructing the evidence the student has difficulty. As for the cause is the students are rarely given a special study of proof and only taught at a glance and unavailability of expected teaching materials. Whereas in Permendikbud in 2014 about syllabus there are some basic competence which demands the existence of proof in geometry at middle school level that is KD 3.4 about material of transformation geometry in class XII of specialization mathematics, KD 3.5 about transformation geometry in class XI math of interest.

the results of nu'man's (2015) "study on developing transformational geometry and sunardi (2014) teaching materials on developing cube and beam learning devices. both studies show that no researcher has developed a teaching material on proof in geometry". so it is necessary to develop a teaching material that can enrich students' knowledge of geometry material.

\section{Research Methods}

Type of research used is research development. The development model used refers to the educational development model of the ADDIE model. This model consists of five stages, namely the stage of analysis, design stage, development stage, implementation stage, and evaluation phase . In the analyze stage (analysis), the researcher performs five things, namely requirement analysis, student characteristic analysis, curriculum analysis, material analysis, and analysis of teaching materials that already exist. Needs analysis is used to analyze the completeness to refine the proven teaching materials designed to fit the needs. Analysis of student characteristics is used to see the initial condition of the students. Curriculum analysis is performed on the material based on the applicable curriculum, the Curriculum 2013 in which there is Core Competence (KI) which is translated into basic competence (KD). Basic competence is selected in accordance with the material to be delivered. Then this basic 
competence is translated into some indicators to be achieved. Material analysis is the identification of key concepts to be taught and systematically arranged. Analysis of this concept can facilitate the teacher later in the learning process and in terms of mastery of the material. Analysis of teaching materials that have been done to get the inspiration and input to the developed teaching materials. Next plan the improvements, changes and improvements needed to address the shortage of existing teaching materials and highlight the characteristics of the teaching materials to be produced.

In the Design stage the researcher designed the prototype of the instructional material that was designed. The design of teaching materials is done on the basis of the results of the analysis phase. At this stage the initial design of teaching materials in the form of prototype $I$.

At the development stage, prototype I is validated by experts and practitioners, and peers. Here the possibility of a cycle, if the material has not been said valid, then the device revised again until the device is declared valid. Validation results resulted in a decent prototype tested at field. Teaching materials developed are said to be valid if the average score obtained and the criteria of the agreement between the minimum validator is at minimum good criteria.

In the implementation stage, the test is done to see the practicality and effectiveness . The teaching material is said to be practical when practitioners based on a practical questionnaire declare the resource practically and the level of implementation in either category.

In the evaluation stage, the data analysis of the practicality and effectiveness of the instructional materials are developed. The tool is said to be effective if at least $80 \%$ positive student response and test result learning reaches completeness criteria of at least $85 \%$.

\section{Results And Discussion}

\subsection{Results}

The process and results of the development of teaching materials are translated from the analyze stage, the design stage, the development stage, the implementation stage and the evaluation stage. On stage analyze obtained some analysis results, namely: (1) Needs analysis obtained $b$ ahwa teachers have never made and received materials proof of geometry of high school students. Teachers want to receive and study the material of proof of geometry in high school. The idea of learning is expected with respect to the proof of geometry of high school students, among others, by providing a stimulus about the examples of new evidence then given LKS (worksheet) to students. The evidentiary problem presented must be consistent from easy to difficult material so as not to confuse the students in the lesson.

The results of the analysis of student characteristics indicate that the students tend to only listen to what is delivered by the teacher and did not find the concepts independently. Some students are active in answering the teacher's questions, but not a few who just silent or even chat with seatmates.

The results of the analysis of the curriculum in 2013 high school class X I obtained that in the face of challenge a $n$ internally through education students are prepared to be transformed from a human source of childbearing age into human resources have the ability competence and skills so they can follow the flow of globalization and development issues of education level international. Teachers are required to build a formal proof of ability on students starting from high school level. From the concept analysis, it is found that the material chosen to be developed is the evident matter in the transformation geometry (translation, reflexology, and rotation) in mathematics of interest. This material is taught in class XII SMA. Teachers have 
never taught any proof of theorems when teaching geometry, most of the theorems only memorize the students without knowing the proof because they think the geometry theorem is quite difficult and difficult to accept by students. Although not so much emphasized as to the proof of geometric theorems, theoretical proofs need to be taught to the students in order to improve their understanding of the geometry of matter.

Result conclusion of concept analysis which is needed in developing teaching material of proving, among others, teacher agrees with researcher opinion that proof of the theorem need to be taught well to students. The teacher agrees that by teaching the proof will make the students more quickly in accepting the meaning of geometry learning. For the analysis of existing teaching materials obtained information that so far there has been no special teaching materials in teaching evidence,

In the Design stage researchers designed a prototype in the form of materials. The design of teaching materials is done on the basis of the results of the analysis phase. At this stage, the initial design of learning device in the form of prototype $I$.

At the development stage, result of validation of developed learning material obtained by average score validator 4,41 (very good category). The validation results indicate that the developed teaching materials have met the valid criteria and deserve to be tested and used as a guide for students and teachers in the learning process after revised according to the advice of the validator.

Implementation stage, the results of field trials obtained the average score of teacher response 3.5 (good) with the level of implementation of $79.48 \%$. The results show that the teaching materials developed have met the practical criteria.

Evaluation stage, result of analysis to questionnaire of student response and test result of learning obtained that $88 \%$ student responded positively and mastery learn reach $86,67 \%$. This shows that the learning tools developed have met the effective criteria.

\subsection{Discussion}

The first evaluation phase of the developed learning materials is validation by experts, practitioners and peers. The indicator used to state that teaching materials are said to be valid is the validity of constructs and content validity by mathematics education experts and education practitioners. Then the validity of a teaching material according to the theoretical and there is internal consistency in each component, in accordance with the opinion of Nieveen and Akker ( 1999 ) which states that the validity aspect refers to whether the developed material has been theoretical and there is internal consistency in each component. Therefore, the components of each validation sheet of the teaching materials are assessed by expert validators, practitioners and peers.

Material validation process is done twice. As for the first validation, the validity level of teaching material is on valid criteria with the average score of 3.33 , but the inter-rater test obtained validations criteria is not valid, because the three validators do not have the same perception of the developed teaching materials, like the first statement, the validator 1 gives a score of 4, while the 2nd and 3rd validators give a score of 3. So also with the other statement, validator 1 and 2 give the same score while the 3 rd validator is different, because there are still some suggestions and comments given. The comment from the expert validator is necessary to add more references because the material is still not complete, there is a sequence that is still wrong in the material. Then the practitioner's comment is that there is no concept map on the teaching materials, some drawings need to be improved, and comments from colleagues it is good for each material to be given a sample problem as an explanation of the given material. 
Therefore, the teaching materials on the first validation are not yet feasible to be tested, still need to be revised and then performed a second validation.

Furthermore, the validation stage of both valid learning materials is based on the average as well as the inter-rater test results. The validity of evidentiary learning tools developed reflected from the analysis of validator assessment where the average total results of teaching materials reached 4.41 which shows validation is on the valid criteria according to predetermined criteria and between all components in learning tools consistent and mutually support each other. This means that learning devices are valid based on the content, that is in accordance with the mathematical syllabus of transformation and geometry based on language, that is in accordance with the prevailing language rules that is the enhanced spelling. Inter-rater reliability tests on teaching materials were analyzed based on prior validation assessments. Assessment of inter-rater reliability test is taken from the assessment between the expert lecturer as the validator 1 (V1), the mathematics teacher as the 2nd validator (V2) and the colleague as validator 3 (V3). Inter-rater reliability test is to analyze the extent of similarity perception between the three validators of learning devices developed.

Test of reliability for teaching materials obtained coefficient kappa V1 and V2 0,41; V1 and V3 0.71 and V2 and V3 0.41 . So the perception between validator 1, validator 2 and validator 3 is the same to the developed teaching material, only a few different statements such as the fifth, eighth, eleventh, twelfth, and fourteen statements mean that the developed material is worthy to be tested.

The teaching materials produced have met the practical criteria based on the response given by the teacher and the observation result of the learning implementation. Observations were made by two teachers who also taught mathematics, while the researchers also acted as observers but did not fill out the observation sheet but wrote down the observations on the researcher's note. The teacher response of teaching materials that have been used is very good, meaning that the material is well executed and easy to use in accordance with Nieveen and Akker (1999) which says that practically can be interpreted that the developed teaching materials can help and provide convenience for its users. Meanwhile, the implementation of the observed learning process also showed good results. The lowest response given by the teacher about the time provided in the learning process is very adequate with a score of 2 , while the response to other statements given a high score of 3 and 4.

Meanwhile, the result of the responses given by the math teacher average score obtained is 3.5 with very good category. This shows that the developed teaching materials are very practical for use in the learning process. Then the observation result given by the observer obtained an average percentage of $79.48 \%$ with the practical category. This suggests that learning tools developed are practically used in the learning process.

Based on field test result conducted by teacher of mathematics subjects in class XII-4 with number of learners 30 students, where teacher and student can use teaching material well indicated by response given by student obtained by mean percentage $88 \%$ with classification very positive. This shows that teaching materials help and facilitate students in understanding the material. Then based on the test results learners learned that from 30 students who tested the results of learning, students who complete 26 students with a percentage of $86.67 \%$ and 4 months unfinished students with a percentage of $13.33 \%$. Exhaustiveness of the test results learned to turn out that many learners who complete exceed $85 \%$, then mastery learners have been achieved. So, overall, the quality of teaching materials developed can be said to be valid, valid, and effective as Nieveen and Akker (1999) say that a material is said to be qualified, if it meets the quality aspects such as (1) validity ( validity) (2) practicality (practically), and (3) the effectiveness (effectiveness). Thus, teaching materials developed qualified in terms of 
valid, practical and effective. Based on the above explanation, it is found that the developed teaching materials can facilitate the students towards the proof of learning. In accordance with the opinion of Ibrahim (Krintanto, 2014) that learning tools are the resources used by teachers and learners in implementing learning. In harmony with Andy (2008) which states that learning tools are a set of media or means used by teachers and learners in the process of learning in the classroom.

\section{Conclusion}

The conclusion of this research is the result of the development of validation material, valid and effective with the criteria a) The validation result by the validator obtained the average score of 4.41 with the valid criterion, b) The result of observation on the learning device implementation and teacher response questionnaire obtained that the teaching materials developed meet the practical criteria with the level of the implementation of the device $79.48 \%$ and the teacher's practical questionnaire 3.5 , and c) The results of data analysis of learners' responses to learning and mastery of learning outcomes of learners obtained that effective teaching materials with positive response category of learners $88 \%$, and learning mastery $86.67 \%$.

\section{References}

[1] NCTM, "Executive summary - Principals and standards for school mathematics," pp. 1-6, 2000.

[2] R. C. Moore, "Making the transition to formal proof," Educ. Stud. Math., vol. 27, no. 3, pp. 249-266, 1994.

[3] G. Polya, "How to Solve It," New Jersey: Princeton University Press, 1985. 